\title{
Correction to: RANKL as a therapeutic target of rheumatoid arthritis
}

\author{
Sakae Tanaka ${ }^{1}\left[\right.$ : Yoshiya Tanaka ${ }^{2}$
}

Published online: 17 December 2020

(c) The Japanese Society Bone and Mineral Research 2020

\section{Correction to: Journal of Bone and Mineral Metabolism https://doi.org/10.1007/s00774-020-01159-1}

In the original publication of the article, the title of Table 1 was published incorrectly. The correct title should read as "Baseline patient demographics and characteristics in DESIRABLE trial. Adopted from Reference \#44 with permission".

In addition, the last sentence in the caption of Fig. 2 was incorrect. The correct sentence should read as "... Adopted from Reference \#44 with permission".

Similarly, the last sentence in the caption of Fig. 3 was incorrect. The correct sentence should read as "... Adopted from Reference \#46 with permission”.
Publisher's Note Springer Nature remains neutral with regard to jurisdictional claims in published maps and institutional affiliations.

The original article can be found online at https://doi.org/10.1007/ s00774-020-01159-1.

Sakae Tanaka

TANAKAS-ORT@h.u-tokyo.ac.jp

1 Department of Orthopaedic Surgery, Faculty of Medicine, The University of Tokyo, 7-3-1 Hongo, Bunkyo-ku, Tokyo 113-0033, Japan

2 First Department of Internal Medicine, University of Occupational and Environmental Health, 1-1 Iseigaoka, Yahatanishi-ku, Kitakyushu, Fukuoka 807-8555, Japan 